\title{
Modulation of Voltage-Gated Conductances of Retinal Horizontal Cells by UV-Excited $\mathrm{TiO}_{2}$ Nanoparticles
}

Xenia Meshik ${ }^{\mathrm{a}, 1,2,3}$, Min Choi ${ }^{\mathrm{b}, 1}$, Adam Baker ${ }^{\mathrm{c}}$, R. Paul Malchow ${ }^{\mathrm{c}, \mathrm{d}}$, Leigha Covnot $^{\mathrm{a}}$, Samuel Doan ${ }^{\mathrm{a}}$, Souvik Mukherjee $^{\text {b }}$, Sidra Farid ${ }^{b}$, Mitra Dutta ${ }^{\text {bee }}$, and Michael A. Stroscio ${ }^{\text {a,b,e }}$

\section{Acknowledgments}

The authors would like to thank Dr. Seyoung An at the Nanotechnology Core Facility at UIC for his help with EFM, as well as Boriana Tchernookova and Ji-in Choi for their help with catfish retinal horizontal cell cultures. 


\begin{abstract}
This study examines the ability of optically-excited titanium dioxide nanoparticles to influence voltagegated ion channels in retinal horizontal cells. Voltage clamp recordings were obtained in the presence and absence of $\mathrm{TiO}_{2}$ and ultraviolet laser excitation. Significant current changes were observed in response to UV light, particularly in the $-40 \mathrm{mV}$ to $+40 \mathrm{mV}$ region where voltage-gated $\mathrm{Na}^{+}$and $\mathrm{K}^{+}$channels have the highest conductance. Cells in proximity to UV-excited $\mathrm{TiO}_{2}$ exhibited a left-shift in the current-voltage relation of around 10 $\mathrm{mV}$ in the activation of $\mathrm{Na}^{+}$currents. These trends were not observed in control experiments where cells were excited with UV light without being exposed to $\mathrm{TiO}_{2}$. Electrostatic force microscopy confirmed that electric fields can be induced in $\mathrm{TiO}_{2}$ with UV light. Simulations using the Hodgkin-Huxley model yielded results which agreed with the experimental data and showed the I-V characteristics of individual ion channels in the presence of UVexcited $\mathrm{TiO}_{2}$.
\end{abstract}

Keywords: Electrostatic force microscopy; Hodgkin-Huxley model; Retinal horizontal cell; $\mathrm{TiO}_{2}$ nanoparticle; Voltage-gated ion channel

Abbreviations: EFM, electrostatic force microscopy; $\mathrm{HH}$, Hodgkin-Huxley; $\mathrm{TiO}_{2}$, titanium dioxide; $\mathrm{UV}$, ultraviolet.

\title{
1. Background
}

Cellular ion currents in excitable cells, such as neurons and muscle cells, are essential for the function of living organisms, as they allow the cells to communicate. These ion currents are possible due to an electrochemical gradient created by varying concentrations of ions inside and outside of the cell. $\mathrm{K}^{+}$is approximately 30 times more concentrated intracellularly than extracellularly, while $\mathrm{Na}^{+}$is approximately 10 times more concentrated extracellularly than intracellularly. This is primarily due to the $\mathrm{Na}^{+} / \mathrm{K}^{+}$pump, which uses energy to transport $3 \mathrm{Na}^{+}$ions out of the cell for every $2 \mathrm{~K}^{+}$ions into the cell. In addition, $\mathrm{K}^{+}$ is allowed to passively flow through leak channels. The unequal ion concentrations inside and outside the cell result in two opposing gradients - a concentration gradient and an electrical gradient. At equilibrium, 
when these two forces negate each other, the electric potential across the membrane is typically around $70 \mathrm{mV}$, known as the resting membrane potential (1).

Because the cell membrane is comprised of a hydrophobic lipid bilayer, hydrophilic particles like ions cannot pass directly through the membrane and instead must rely on a variety of channels. In addition to the $\mathrm{K}^{+}$leak channels mentioned above, which open and close randomly, several other types of ion channels exist. Ligand-gated ion channels open upon binding to a specific receptor. Glutamate-gated channels, for instance, open when bound to the neurotransmitter glutamate and play a major role in excitatory signaling in the brain (2). Mechanically activated channels exist in the inner ear and open in response to sound waves (1). This study focuses on voltage-gated ion channels, which open in response to changes in membrane potential.

Retinal horizontal cells are neuronal cells found in the retina that are responsible for enhancing visual contrast (3). Horizontal cells from channel catfish retina were used in this study due to their large flat morphology, which makes them ideal for whole cell patch clamp recordings. These cells display six types of ion currents. $\mathrm{Na}^{+}$current is activated in response to membrane depolarization. Its threshold is around $50 \mathrm{mV}$, and depolarizing voltages beyond the threshold of activation of these channels result in a positive current from $\mathrm{Na}^{+}$flow into the cell. This creates a positive feedback loop, further depolarizing the membrane. An L-type $\mathrm{Ca}^{2+}$ current, which activates at around $-30 \mathrm{mV}$, also flows into the cell and contributes to membrane depolarization. Whereas $\mathrm{Na}^{+}$conductance only lasts several milliseconds (4), $\mathrm{Ca}^{2+}$ current can last much longer, though it is small in magnitude compared to $\mathrm{Na}^{+}$current $(5,6)$.

Several $\mathrm{K}^{+}$currents are responsible for repolarizing the membrane. Transient outward $\mathrm{K}^{+}$current is rapidly activated and consists of $\mathrm{K}^{+}$moving out of the cell during membrane repolarization. Delayed rectifying $\mathrm{K}^{+}$channels open slowly and play a large role in repolarization by enabling $\mathrm{K}^{+}$flow out of the cell to the point where the membrane is hyperpolarized. Anomalous rectifying $\mathrm{K}^{+}$current is activated by hyperpolarization and consists of $\mathrm{K}^{+}$flowing into the cell to bring the membrane voltage back to resting 
potential $(1,6)$. Leak currents are not voltage dependent and simply operate according to Ohm's law to maintain resting membrane potential.

A number of studies have been done on factors that can affect the activation voltage of voltage-gated ion channels (7-10), since the ability to influence the activation dynamics could have potential applications for a variety of diseases affecting voltage-gated ion channels, such as epilepsy or cardiac arrhythmia (11), human genetic diseases $(12,13)$, neuropathic pains $(14)$, etc. A typical example of the modification of the activation dynamics of voltage-gated ion channels is the shift in current-voltage (I-V) characteristics. Theoretically, the shift in I-V characteristics influences significantly the cellular excitation (12) and inactivation mechanism (13). Bendahhou et al showed that the slow inactivation of the voltage-gated sodium channel is the primary cause of autosomal dominant skeletal muscle disorder (13). Thus, the importance of the ability to alter the dynamics of the voltage-gated ion channels cannot be over emphasized. Nanoparticles can be used as a tool in basic science research into these diseases, as they can be remotely optically activated to simulate abnormal ion channel dynamics such as the ones found in the above-mentioned diseases.

In this work, $\mathrm{TiO}_{2}$ nanoparticles are used in conjunction with retinal horizontal cells to study the effects of light-induced electric field on the behavior of voltage-gated ion channels. Previous theoretical work has postulated on semiconductor nanoparticles' ability to influence voltage-gated ion channels with their polarization $(15,16)$. It has been shown that neurons grown on HgTe nanoparticle-containing films experience action potentials when irradiated with light (17). CdS nanoparticles have also been shown to cause ion channel activation when excited optically (18). Nanoparticles are, therefore, promising tools for controlling ion channel behavior. Since $\mathrm{TiO}_{2}$ is more biocompatible than heavy metal materials, its potential as a tool to control I-V characteristics in living cells will be of interest to researchers.

Electrostatic force microscopy (EFM) and theoretical modeling are used in this work to confirm experimentally observed trends. While a number of studies has been done to characterize individual 
voltage-gated conductances in horizontal cells, a comprehensive theoretical description of ion channel behavior in these cells is lacking. Such a theoretical description could help reveal fundamental characteristics of ion channel behavior, especially under circumstance where such channel activity could be modulated by the influence of nanoparticles. In this work, an electrical model of a horizontal cell in the absence and presence of $\mathrm{TiO}_{2}$ nanoparticles is proposed based on our experimental data. Both experimental results and theoretical modeling show that $\mathrm{UV}$-induced electric fields of $\mathrm{TiO}_{2}$ nanoparticles can influence the activation of voltage-gated ion channels as long as the QDs are in close proximity to ion channels.

\section{Methods}

\subsection{Cell culture}

Channel catfish were obtained from Keystone Hatcheries (Richmond, IL) and from Wing Lee Co. (Chicago, IL). Fish were dark adapted for at least an hour before use, anesthetized with a solution of approximately $1 \mathrm{~g}$ /gallon of ethyl 3-aminobenzoate methanesulfonate (Sigma Aldrich, St. Louis, MO) and $2.5 \mathrm{~g} / \mathrm{gallon}$ of sodium bicarbonate (Sigma Aldrich, St. Louis, MO), and sacrificed by cervical transection and pithing. Retinal horizontal cells were obtained with previously described protocols $(19,20)$. Both eyes were removed, sliced in half, and the posterior half was immersed in a solution containing approximately $1 \mathrm{mg} / \mathrm{mL}$ papain (Acros Organics, Fair Lawn, NJ) and $0.5 \mathrm{mg} / \mathrm{mL}$ L-cysteine (Sigma Aldrich, St. Louis, MO). After 30 min, retinas were removed and rinsed 8 times in Ringer's solution containing $126 \mathrm{mM} \mathrm{NaCl}, 4 \mathrm{mM} \mathrm{KCl}, 3 \mathrm{mM} \mathrm{CaCl}_{2}, 1 \mathrm{mM} \mathrm{MgCl} 2,15 \mathrm{mM}$ dextrose, and $10 \mathrm{mM} \mathrm{HEPES}$, $\mathrm{pH}$ 7.4. The retinas were then dissociated by gentle agitation with a glass pipette. After around 15 seconds of agitation, the supernatant, containing primarily photoreceptors, was removed and discarded. The remainder of the retinas, containing primarily horizontal cells, was agitated for an additional 30 seconds. The resulting suspension was placed in $35-\mathrm{mm}$ cell culture dishes containing $4 \mathrm{~mL}$ of Ringer's solution 
(approximately 2 drops of suspension per dish). The dishes were kept at $14^{\circ} \mathrm{C}$ until use and recordings were obtained on the same day.

\subsection{Whole Cell Patch Clamp Recordings}

Whole cell patch clamp recordings were obtained using a HEKA EPC 10 USB amplifier (Holliston, MA). Glass capillaries (Sutter Instruments, Novato, CA) were pulled to form pipettes with resistances of 4-8 $\mathrm{M} \Omega$ and filled with intracellular solution containing $110 \mathrm{mM} \mathrm{KCl}, 0.5 \mathrm{mM} \mathrm{CaCl}, 5 \mathrm{mM}$ EGTA, and 10 $\mathrm{mM}$ HEPES. The $\mathrm{pH}$ was adjusted to 7.0 using $\mathrm{KOH}$. Once the pipette was brought into contact with the cell, suction was applied to create a gigaohm seal and rupture the membrane.

For recordings obtained with $\mathrm{TiO}_{2}, 140 \mathrm{mM} \mathrm{TiO}$ nanoparticles (Sigma Aldrich, St. Louis, MO) were added to the dish after successful formation of the gigaohm seal. A 325-nm and 442-nm dual wavelength 100-mW IK Series He-Cd Laser (Kimmon Electric Company, Tokyo, Japan) was shined on the cell to excite the nanoparticles (Figure 1). Voltage pulses from $-110 \mathrm{mV}$ to $60 \mathrm{mV}$, each lasting $200 \mathrm{~ms}$, were applied sequentially and the resulting current readings were recorded using HEKA Patchmaster acquisition software. When voltage-gated currents begin to flow through the membrane, the amplifier applies an equal and opposite current necessary to maintain the cell at the set voltage. Voltage-activated ion currents can thus be measured.

Recordings were obtained with and without laser excitation, and the minimum current during the first 15 ms was used to plot I-V curves, since the maximum inward current due to $\mathrm{Na}^{+}$conductance occurs during this time period. A total of 12 different data sets were obtained from different cells. In addition, 12 control trials were performed in the absence of $\mathrm{TiO}_{2}$ to confirm that any change in channel conductance was not caused by UV light itself.

\subsection{Electrostatic Force Microscopy Studies of $\mathrm{TiO}_{2}$}


EFM was used to confirm that $\mathrm{TiO}_{2}$ nanoparticles were, in fact, generating electric fields in response to UV light. $\mathrm{TiO}_{2}$ nanoparticles were dropcast onto a gold-coated silicon substrate and imaged using Bruker Dimension Icon AFM (Billerica, MA). A SCM-PIT probe was used to first obtain a topological image of the sample in contact mode. The sample was then scanned in lift mode with a lift height of $10 \mathrm{~nm}$ and the interleave amplitude data was used to observe any change in distance between the tip and the sample. Scans were obtained with and without illumination by a handheld laser.

\section{Results}

\subsection{Whole Cell Voltage Clamp Recordings}

A typical whole cell voltage clamp recording is shown in Figure 2. For applied voltages below $-70 \mathrm{mV}$, there is net negative current, or an influx of positive ions into the cell. This inward current is caused primarily by inwardly rectifying $\mathrm{K}^{+}$channels that are activated by hyperpolarizating voltages. At resting membrane potential (around $-70 \mathrm{mV}$ ), the cell is at equilibrium and there is no net current flow. Progressive depolarizing steps lead to activation of the, voltage-gated activation of $\mathrm{Na}^{+}$channels (inward currents), as $\mathrm{Na}^{+}$rapidly flows into the cell due to the high concentration gradient, resulting in a large negative current which is represented by the green trace corresponding to $\mathrm{V}=0 \mathrm{mV}$ in the inset of Figure 2b. Voltage-gated $\mathrm{K}^{+}$channels are also opening at this time, but the $\mathrm{Na}^{+}$conductance dominates, which explains the net negative current. At membrane potentials of greater than $30 \mathrm{mV}, \mathrm{K}^{+}$currents dominate; current flow through $\mathrm{Na}^{+}$channels is small near the Nernst equilibrium potential for $\mathrm{Na}^{+}$, so the net current is positive $(1,21)$. The large transients of positive or negative current at the beginning and end of the voltage pulse are capacitive currents caused by rearrangement of charges at the membrane (21), and they can be ignored for the purposes of this experiment. 
In the presence of $\mathrm{TiO}_{2}$, a noticeable shift in the voltage associated with maximum $\mathrm{Na}^{+}$conductance can be seen, as shown in a representative plot in Figure 3a, which is consistent with the Hodgkin-Huxley model discussed in Section 3.3. Whereas the maximum inward current occurred at around $0 \mathrm{mV}$ prior to laser UV excitation, with laser excitation it shifted in the negative direction to around $-10 \mathrm{mV}$. This shift was not observed in the control experiments performed in the absence of $\mathrm{TiO}_{2}$ (Figure $3 b$ ). It is clear that the presence of both $\mathrm{TiO}_{2}$ and UV light is necessary for the shift to occur, suggesting that it occurs due to the optical excitation and resulting polarization of $\mathrm{TiO}_{2}$.

The effect of UV-excited $\mathrm{TiO}_{2}$ on voltage-gated currents is also noticeable when looking at the current change at each voltage in response to laser light. Figure 4 shows the light-induced current change in the presence and absence of $\mathrm{TiO}_{2}$ nanoparticles. In the -30 to $+40 \mathrm{mV}$ region, where voltage-gated $\mathrm{Na}^{+}$and $\mathrm{K}^{+}$channels display their highest conductance, the currents change by as much as $84 \mathrm{pA}$ for $\mathrm{V}=0 \mathrm{mV}$, compared to 10 in the case of the control. The large standard deviations indicated by error bars in the case of $\mathrm{TiO}_{2}$-exposed cells likely reflect the fact that the distance between nanoparticles and ion channels varies from cell to cell, and thus the strength of the electric field sensed by the voltage-gated ion channels is not consistent. The relatively small light-induced current changes in the control experiment can be explained by natural fluctuation in currents that occurs in all cells even in the absence of any external factors (22).

\subsection{UV-Induced Electric Fields in $\mathrm{TiO}_{2}$}

EFM measurements confirm the presence of electric fields in $\mathrm{TiO}_{2}$ nanoparticles when exposed to light. Figure 5 shows that the interleave amplitude, or the scanning probe's distance from the sample, increased by around $0.4 \mathrm{~nm}$ upon illumination with the laser, suggesting that an electrostatic force repels the tip from the surface of the nanoparticle film (23). This is in agreement with previously-published studies on optically-induced electric fields in $\mathrm{TiO}_{2}$ (24). While quantifying the electric field based solely on 
interleave amplitude shift involves multiple approximations and assumptions, EFM is nonetheless a useful tool for qualitatively observing electric field.

In addition to EFM measurements, theoretical modeling was used to confirm experimental results.

\subsection{Hodgkin and Huxley Model}

Hodgkin and Huxley proposed an electrical circuit model (HH model) of a cell membrane from a squid axon with two different types of voltage-gated ion channels in 1952 (25). In the HH model, current from an individual ion channel is described by equation with the membrane potential and a set of first order differential equations which can be empirically fitted well with the experimental data. That is,

$$
I_{i}=g_{i}^{\max } \times m_{n}(V, t) \times h_{p}(V, t) \times\left(V-E_{i}\right)
$$

where $i$ is the type of ion channel, $E_{i}$ is the reverse potential of $i$ type of ion channel, $m_{n}(V, t)$ and $h_{p}(V, t)$ are activation and inactivation constants, respectively, and $n$ and $\mathrm{p}$ are power constants. These constants are given by:

$$
\begin{gathered}
\frac{d m_{i}}{d t}=\alpha_{m_{i}}(V) \times\left(1-m_{i}(t)\right)-\beta_{m_{i}}(V) \times m_{i}(t) \\
\frac{d h_{i}}{d t}=\alpha_{h_{i}}(V) \times\left(1-h_{i}(t)\right)-\beta_{h_{i}}(V) \times h_{i}(t)
\end{gathered}
$$

where $\alpha$ 's and $\beta$ 's are empirical parameters that are tunable to designated behavior of ion channels. The parameters used in this work are summarized in Table 1 . The total ionic current in a cell is given by the sum of currents from all individual ion channels plus the capacitive current due to the change of the membrane potential in time:

$$
I_{\text {ion }}^{\text {total }}=C_{\text {membrane }} \frac{d V}{d t}+\sum_{i} I_{i}(V, t)
$$


With the presence of a nanoparticle that produces electrostatic field, this equation becomes

$$
I_{\text {ion }}^{\text {total }}=C_{\text {membrane }} \frac{d V}{d t}+\sum_{i} I_{i}\left(V+V_{Q D}, t\right)
$$

To model the electric field from $\mathrm{TiO}_{2}$, a nanoparticle is assumed to be a sphere. When it is in an intense laser field, electron and hole pairs are created. As a result, it is polarized uniformly along the polarization direction of the laser. This phenomena is referred to as induced polarization, which is mathematically described by

$$
\vec{P}=\alpha \vec{E}
$$

where $\alpha=\left[1-\frac{\sqrt{E_{g}}}{4.06}\right] \frac{M}{\rho} \times 4.4060 \times 10^{-35} F \cdot m^{2}(25), \vec{E}$ is the laser field, and $E_{g}, M$, and $\rho$ are the band gap, molecular weight, and density of the nanoparticle, respectively. Then the surface charge, $\sigma$, is calculated by

$$
\sigma=\vec{P} \cdot \hat{n}=P \cos (\theta)
$$

The laser field is calculated from the intensity of laser used in the experiment, the total power of which is $100 \mathrm{~mW}$, by the relationship between the time average of energy density of laser and the amplitude of electric field which is given by

$$
|\mathrm{E}|^{2}=\frac{2 I}{c n \epsilon_{0}}
$$

where $I$ is the intensity per unit area, $c$ is the speed of light, $n$ is the refractive index of the media, and $\epsilon_{0}$ is vacuum permittivity.

Then, the electric field produced from a $\mathrm{TiO}_{2}$ nanoparticle can be calculated by solving Gauss's law (26): 


$$
\mathrm{E}_{Q D}^{\text {induced }}=\frac{P_{\text {induced }}}{3 \epsilon} \frac{R^{3}}{r^{3}}[2 \cos (\theta) \hat{r}+\sin (\theta) \hat{\theta}], r>R
$$

where $\epsilon$ is the dielectric function of the media and $R$ is radius of a nanoparticle. In water-based electrolytes, the screening effect has to be considered as an exponential decay:

$$
\mathrm{E}_{Q D}^{\text {electrolyte }}=\mathrm{E}_{Q D}^{\text {induced }} e^{-\frac{(r-R)}{\lambda_{D}}}
$$

\begin{tabular}{|c|c|c|c|c|c|c|c|}
\hline & $\alpha_{m}$ & $\beta_{m}$ & $\alpha_{h}$ & $\beta_{h}$ & $g_{\max }[n S]$ & $E_{i}[\mathrm{mV}]$ & $I_{\text {ion }}$ \\
\hline $\begin{array}{c}\text { Transient } \\
\text { outward } \mathrm{K}^{+} \\
\text {current }(27, \\
28)\end{array}$ & $\frac{24}{1+e^{-\frac{V-50}{28}}}$ & $8 e^{-\frac{V}{36}}$ & $0.5 e^{-\frac{V}{60}}$ & $\frac{0.4}{1+e^{-\frac{V+40}{5}}}$ & 3.0 & -80 & $\begin{array}{l}g_{K v} m_{K v}^{3} h_{K v}(V \\
\left.-E_{K v}\right)\end{array}$ \\
\hline $\begin{array}{c}\text { Delayed } \\
\text { rectifying } \\
\mathrm{K}^{+} \text {current } \\
(27-29)\end{array}$ & $\frac{4.0(65-V)}{e^{\frac{65-V}{50}}-1}$ & $48 e^{\frac{45-V}{85}}$ & $\frac{30}{1+e^{\frac{V+92}{7}}}$ & $\frac{16}{1+e^{\frac{V+100}{15}}}$ & 22.0 & -80 & $\begin{array}{l}g_{A} m_{A}^{4} h_{A}(V \\
\left.-E_{A}\right)\end{array}$ \\
\hline $\begin{array}{c}\text { Anomalous } \\
\text { rectifying } \\
\mathrm{K}^{+} \text {current } \\
(27,28)\end{array}$ & & $m_{K a}=$ & $\frac{1}{+e^{\frac{V+60}{12}}}$ & & 4.5 & -80 & $\begin{array}{l}g_{K a} m_{K a}^{5}(V \\
\left.-E_{K a}\right)\end{array}$ \\
\hline $\begin{array}{c}\mathrm{Ca}^{2+} \text { current } \\
\text { (29) }\end{array}$ & $\frac{5(70-V)}{e^{\frac{70-V}{28}}-1}$ & $2 e^{-V / 15}$ & $h_{C a}=\frac{}{[l}$ & $\frac{[K]}{+[C a]_{\text {out }}}$ & 30.0 & $12.9 \log _{\overline{[}}$ & $\begin{array}{l}g_{C a} m_{C a}^{4} h_{C a}(V \\
\left.-E_{C a}\right)\end{array}$ \\
\hline
\end{tabular}

$\lambda_{D}$ is the Debye length which can be written by 
Table 1. Summary of parameters used in HH model.

$$
\lambda_{\mathrm{D}}=\sqrt{\frac{\epsilon k_{B} T}{2 N_{A} e^{2} I}}
$$

where $k_{B}$ is Boltzmann constant, $T$ is temperature, $N_{A}$ is Avogadro's number, $e$ is elementary charge, and $I$ is ionic strength of the electrolyte, which is given by $I=\frac{1}{2} \sum_{i=1}^{n} c_{i} z_{i}^{2}$, and $c_{i}$ is the molar concentration of the $i$ th ion in the electrolyte and $z_{i}$ is the charge of the $i$ th ion.

Our simulation shows that in retinal horizontal cells the addition of an excited $\mathrm{TiO}_{2}$ nanoparticle results in a left shift of the I-V characteristics along the voltage axis, in the case when the polarization axis of the nanoparticle is perpendicular to the membrane and the nanoparticle is $1 \mathrm{~nm}$ away from the ion channel. In Figure 6, I-V characteristics of a horizontal cell are plotted which represent the total ion currents in response to the applied membrane potential. Inset of Figure 6 represents the magnification near the local minima where $\mathrm{Na}^{+}$channels play the major role. The voltage associated with the minimum current is shifted to the left in the presence of the excited nanoparticle compared to without nanoparticles. The shifts of I-V characteristics also appear in case of individual ion channels, as shown in Figure 7. For each ion channel, the I-V curves shifted to the left in the range that the specific channel is activated with addition of $\mathrm{TiO}_{2}$. For example, the activation range of the voltage gated anomalous rectifying $\mathrm{K}^{+}$channel is below potentials of $-40 \mathrm{mV}(30)$, and there is a clear shift of $\mathrm{I}-\mathrm{V}$ characteristics to the left in this range.

The behavior of individual ion currents (Figure 7) in the presence of nanoparticles can be used to explain 
the trends observed experimentally (Figure 3). The minor left-shift in I-V curve observed experimentally in the $-110 \mathrm{mV}$ to $-70 \mathrm{mV}$ range can be attributed to anomalous rectifying $\mathrm{K}^{+}$channels. The shift in the I$\mathrm{V}$ curve in $-40 \mathrm{mV}$ to $+20 \mathrm{mV}$ range is due to voltage-gated $\mathrm{Na}^{+}$and $\mathrm{Ca}^{2+}$ channels, the conductances of which dominate in this range.

Although this simulation is specific to retinal horizontal cells, the parameters can be easily adjusted to predict the behaviors of other cell types in response to induced electric fields or other external stimuli. This is potentially relevant in medical applications for treatment of ion-channel related diseases.

\section{Discussion}

In this work, optically-excited $\mathrm{TiO}_{2}$ nanoparticles are shown to influence the opening of voltage-gated ion channels in retinal horizontal cells by shifting the cell's I-V characteristics to more negative voltage values. This trend is especially strong in the physiologically relevant region of $-30 \mathrm{mV}$ to $+40 \mathrm{mV}$, where voltage-gated $\mathrm{Na}^{+}$and $\mathrm{K}^{+}$channels display the highest conductance. EFM measurements and theoretical modeling confirmed that this is due to the electric fields generated by optically-excited $\mathrm{TiO}_{2}$ nanoparticles located in close proximity to the ion channels.

The structural properties of $\mathrm{TiO}_{2}$ can give insight into its influence on voltage-gated ion channel activation. $\mathrm{TiO}_{2}$ is a semiconductor material with a large band gap of around $3.2 \mathrm{eV}$ for the anatase form, which allows it to be used in a variety of applications involving light absorption, including sun protection, photocatalysts, and solar energy production (31). $\mathrm{TiO}_{2}$ is an indirect bandgap material, meaning an electron excited to a higher energy band cannot recombine with a hole without first undergoing a phononaided change in momentum (32). Due to this structural property, $\mathrm{TiO}_{2}$ rarely exhibits radiative recombination of electrons and holes as observed in direct bandgap materials, and as a result rarely emits 
light. Instead, the separation of carriers contributes to the formation of a dipole moment and, subsequently, an electric field around the $\mathrm{TiO}_{2}$ particle.

A shift in cellular activation voltage similar to one observed in this work has been previously reported in response to a variety of factors. It has been shown that protonation enhances $\mathrm{Na}^{+}$conductance (8) and $\mathrm{Ca}^{2+}$ conductance (9) in retinal horizontal cells, resulting in a shift in voltage associated with maximum inward current. This is likely due in part to $\mathrm{H}^{+}$screening the negative charges near the membrane, with the resulting change in electrochemical gradient leading to a shift in activation potential (33). Similarly, studies involving mutant $\mathrm{K}^{+}$channels which were missing either the $\mathrm{N}$ or $\mathrm{C}$ terminus of the channel showed in a shift in activation voltage (7). While the exact mechanism of modulation of many voltagegated channels is still under debate, it is largely believed that the voltage sensing occurs due to reorientation of positively and negatively charged subunits of the ion channel in response to potential changes, resulting in opening or closing of the channel (21). It is, therefore, reasonable that the presence of protons or the absence of a charged terminus would cause a change in the channel's conductance. In our case, the electric fields from optically-excited $\mathrm{TiO}_{2}$ affect the channels in a similar manner by introducing an induced electrostatic potential, altering the orientation of the charged subunits and causing the channel to open or close.

The distance between a nanoparticle and the ion channel plays a large role in this phenomenon. The strength of the electric field generated by polarized $\mathrm{TiO}_{2}$ decreases exponentially with distance due to screening by the electrolyte (26), in this case the Ringer's solution, so it is imperative for the $\mathrm{TiO}_{2}$ to be in close proximity to the ion channel in order for the voltage shift to occur. For this reason, a $\mathrm{TiO}_{2}$ concentration of $140 \mathrm{mM}$ was used in our study. Despite this high concentration, the cells still exhibited the expected I-V characteristics (Figure 3), showing that on the time scale of the experiment the large amount of $\mathrm{TiO}_{2}$ did not have adverse effects on cellular ion channel behavior. $\mathrm{TiO}_{2}$ has low toxicity compared to many other semiconductor materials, hence its use as a UV light absorbent in a variety of products such as sunscreen and cosmetics (34). Nevertheless, it has been shown that prolonged (24 hours) 
exposure to $\mathrm{TiO}_{2}$ nanoparticles can effect mitochondrial function (35), and two-year exposure to high concentrations of $\mathrm{TiO}_{2}$ nanoparticles has been found to cause pulmonary lesions in rats (36). UVphotoactivated $\mathrm{TiO}_{2}$ nanoparticles have also been shown to generate reactive oxygen species (ROS) which could make cells more susceptible to bacterial invasion (37) and cause other cell damage after several hours of exposure (38-40). While no adverse effects were observed on the time scale of the experiment, more research is needed before implementing photoactive $\mathrm{TiO}_{2}$ in long-term studies or therapeutics. Future studies could also benefit from using ligand-functionalized nanoparticles, followed by washing away of unbound nanoparticles, which would minimize the $\mathrm{TiO}_{2}$ concentration while insuring its proximity to membrane ion channels. Nevertheless, the method shown here is promising for basic science research and in vitro experiments into ion channel diseases.

Among other methods of controlling voltage-gated ion channel activation is optogenetics, a field that relies on genetic modification of cells through introduction of foreign DNA in order to express lightactivated proteins. Channelrhodopsins are light-activated cation channels that were discovered in algae (41) and have since been used extensively for optically controlling neuronal excitability. Numerous mutants of channelrhodopsins have since been created, including some allowing for greater selectivity for specific cations $(42,43)$, some that are activated by different wavelengths of light (44) and some that can also be optically deactivated as well as activated (45). Optogenetic tools clearly have an advantage of being extremely customizable. However, they involve genetic manipulation of cells through transfection, which often affects the long-term survival of cells, and the transfection protocols for less widely-used cell lines often require time-consuming optimization.

Voltage-gated ion channels have also been controlled via photochromic ligands (PCLs), small molecules that bind to the inside of the ion channel and change conformation upon light absorption, thereby either blocking or allowing the flow of ions (46). Like optogenetics, this method allows for some tuning, since different PCLs are selective for different ion channels. However, delivery of the PLCs to the cell can be problematic, since extracellular PLCs can only enter the cell through specific channels which are not 
present in all cell types, requiring exogenous expression of these channels in cell types where they are not native. A variant of PCLs exists that covalently binds to extracellular regions of the ion channels it modulates, but this requires mutation of the ion channel (46).

Thus, while some tools such as optogenetics and PCLs have the advantage of being highly customizable and specific in their ability to optically switch voltage-gated ion channels, the nanoparticle method described in this work is noninvasive and can be easily implemented with a variety of cell types. As mentioned earlier, HgTe (17) and CdSe (18) nanoparticles have been successfully used for this purpose. Other studies have used gold nanoparticles, which emit heat upon light absorption and thereby alter the membrane capacitance (47). Together, these studies show that voltage-gated ion channel characteristics can be controlled with a variety of nanoparticles and light wavelengths. While further optimization of the $\mathrm{TiO}_{2}$ method is needed due to potential long-term adverse effects on cells, this method is nonetheless useful for altering I-V dynamics in short time scale experiments investigating diseases affecting voltagegated ion channels. Moreover, these results indicate that it may be possible to modify or control the physiological behavior of cellular and neuronal ion channels, potentially opening the way to modifying ion channel behaviors in ways that impact cellular and neuronal functions in both diseased and healthy cells. 


\section{Figure Legends}

Figure 1. Schematic of whole cell patch clamp recordings performed in this study. EGTA in the intracellular fluid serves as a $\mathrm{Ca}^{2+}$ chelator, effectively making the free $\mathrm{Ca}^{2+}$ concentration in $\mathrm{nM}$ range. A gigaohm seal is created by bringing the electrode-containing glass capillary to the cell membrane and applying suction until the membrane inside the pipette is ruptured. The membrane can then be maintained at a set voltage point $\left(\mathrm{V}_{\mathrm{cmd}}\right)$ through a current generated by the amplifier.

Figure 2. Typical whole cell voltage clamp recordings. A series of $200-\mathrm{ms}$ voltage pulses from -110 to +60 $\mathrm{mV}$ in magnitude are applied sequentially (a). The corresponding current traces are recorded (b). The initial portion contained within the red rectangle is enlarged (c) to better examine the voltageactivated $\mathrm{Na}^{+}$currents and the subsequent repolarizing $\mathrm{K}^{+}$currents which dominate the membrane 
conductance in this range. The minimum current readings from the $15-25 \mathrm{~ms}$ range are plotted against the applied voltage to obtain an I-V curve (d).

Figure 3. Representative I-V plots obtained from whole cell recordings in the presence (a) and absence (b) of $\mathrm{TiO}_{2}$. Black traces were obtained with the laser off and red with the laser on. A shift in the voltage associated with the maximum $\mathrm{Na}^{+}$conductance can be seen in the presence of UV-excited $\mathrm{TiO}_{2}$. This trend was observed in 6 out of the 12 cells tested.

Figure 4. Changes in current (current with laser off minus current with laser on) in response to UV laser excitation in the presence (red) and absence (black) of $\mathrm{TiO}_{2}$. Cells exposed to UV-excited $\mathrm{TiO}_{2}$ experience significant current shifts at membrane voltages in the range of -40 to $+40 \mathrm{mV}$, where voltage gated $\mathrm{Na}^{+}$and $\mathrm{K}^{+}$channels are most conductive. Error bars represent standard deviations from 6 data sets.

Figure 5. Electric fields in $\mathrm{TiO}_{2}$ nanoparticles induced by UV light can be detected via EFM. (a) shows the topology of dropcasted $\mathrm{TiO}_{2}$ suspension on a Au-coated $\mathrm{Si}$ substrate. (b) shows the interleave amplitude of probe in the absence of UV light. (c) shows the interleave amplitude of the probe in the presence of UV light from a handheld laser. The corresponding interleave amplitude profiles along the dashed segment are displayed on the left.

Figure 6. I-V characteristics of a horizontal cell, which represent the total ion currents in response to the applied membrane potentials. Inset figure is the magnification near the local minima where $\mathrm{Na}^{+}$channels play the major role. The minimum point with $\mathrm{TiO}_{2}$ is shifted to the left compared to that without $\mathrm{TiO}_{2}$.

Figure 7. I-V characteristics of individual ion channels in a horizontal cell. For each ion channel, the I-V curves shifted to the left in the range that the specific channel is activated with addition of $\mathrm{TiO}_{2}$. 


\section{References}

1. Alberts B. Essential Cell Biology: Garland Science; 2010.

2. Dingledine R, Borges K, Bowie D, Traynelis SF. The glutamate receptor ion channels. Pharmacol Rev. 1999;51(1):7-61.

3. Masland RH. The fundamental plan of the retina. Nat Neurosci. 2001;4(9):877-86.

4. Hodgkin AL, Huxley AF, Katz B. Measurement of current-voltage relations in the membrane of the giant axon of Loligo. J Physiol. 1952;116(4):424-48.

5. Takahashi K, Dixon DB, Copenhagen DR. Modulation of a sustained calcium current by intracellular pH in horizontal cells of fish retina. J Gen Physiol. 1993;101(5):695-714. 
6. Foa PP, Walsh MF. Ion Channels and Ion Pumps: Metabolic and Endocrine Relationships in Biology and Clinical Medicine: Springer New York; 2011.

7. Marten I, Hoshi T. Voltage-dependent gating characteristics of the K+ channel KAT1 depend on the N and C termini. Proc Natl Acad Sci U S A. 1997;94(7):3448-53.

8. Jonz MG, Barnes S. Proton modulation of ion channels in isolated horizontal cells of the goldfish retina. J Physiol. 2007;581(Pt 2):529-41.

9. Hirasawa H, Kaneko A. pH changes in the invaginating synaptic cleft mediate feedback from horizontal cells to cone photoreceptors by modulating Ca2+ channels. J Gen Physiol. 2003;122(6):65771.

10. Strege PR, Bernard CE, Kraichely RE, Mazzone A, Sha L, Beyder A, et al. Hydrogen sulfide is a partially redox-independent activator of the human jejunum Na+ channel, Nav1.5. Am J Physiol Gastrointest Liver Physiol. 2011;300(6):G1105-14.

11. Hubner CA, Jentsch TJ. Ion channel diseases. Hum Mol Genet. 2002;11(20):2435-45.

12. Combs DJ, Shin HG, Xu Y, Ramu Y, Lu Z. Tuning voltage-gated channel activity and cellular excitability with a sphingomyelinase. J Gen Physiol. 2013;142(4):367-80.

13. Bendahhou S, Cummins TR, Tawil R, Waxman SG, Ptacek LJ. Activation and inactivation of the voltage-gated sodium channel: role of segment S5 revealed by a novel hyperkalaemic periodic paralysis mutation. J Neurosci. 1999;19(12):4762-71.

14. Dib-Hajj SD, Cummins TR, Black JA, Waxman SG. Sodium channels in normal and pathological pain. Annu Rev Neurosci. 2010;33:325-47.

15. Alexson D, Chen H, Cho M, Dutta M, Li Y, Shi P, et al. Semiconductor nanostructures in biological applications. Journal of Physics: Condensed Matter. 2005;17(26):R637.

16. Stroscio MA, Dutta M, Narwani K, Shi P, Ramadurai D, Kohanpour B, et al. Integrating and Tagging Biological Structures with Nanoscale Semiconductor Quantum dot Structures. In: Stroscio MA, Dutta M, editors. Biological Nanostructures and Applications of Nanostructures in Biology: Electrical, Mechanical, and Optical Properties. Boston, MA: Springer US; 2004. p. 1-36. 
17. Pappas TC, Wickramanyake WM, Jan E, Motamedi M, Brodwick M, Kotov NA. Nanoscale engineering of a cellular interface with semiconductor nanoparticle films for photoelectric stimulation of neurons. Nano Lett. 2007;7(2):513-9.

18. Winter JO, Gomez N, Korgel BA, Schmidt CE, editors. Quantum dots for electrical stimulation of neural cells. Nanobiophotonics and Biomedical Applications II; 2005: SPIE.

19. Jacoby J, Kreitzer MA, Alford S, Qian H, Tchernookova BK, Naylor ER, et al. Extracellular pH dynamics of retinal horizontal cells examined using electrochemical and fluorometric methods. J Neurophysiol. 2012;107(3):868-79.

20. Kreitzer MA, Collis LP, Molina AJ, Smith PJ, Malchow RP. Modulation of extracellular proton fluxes from retinal horizontal cells of the catfish by depolarization and glutamate. J Gen Physiol. 2007;130(2):169-82.

21. Bezanilla F. How membrane proteins sense voltage. Nat Rev Mol Cell Biol. 2008;9(4):323-32.

22. Lewenstam A, Gorton L. Electrochemical processes in biological systems. Hoboken, New Jersey: Wiley; 2015. x, 255 pages $\mathrm{p}$.

23. Choi MS, Meshik X, Dutta M, Stroscio MA, editors. Screening effect on electric field produced by spontaneous polarization in $\mathrm{ZnO}$ quantum dot in electrolyte. Computational Electronics (IWCE), 2015 International Workshop on; 2015 2-4 Sept. 2015.

24. Lana-Villarreal T, Bisquert J, Mora-Sero I, Salvador P. Experimental evidence of a UV lightinduced long-range electric field in nanostructured $\mathrm{TiO} 2$ thin films in contact with aqueous electrolytes. J Phys Chem B. 2005;109(20):10355-61.

25. Hodgkin AL, Huxley AF. A quantitative description of membrane current and its application to conduction and excitation in nerve. J Physiol. 1952;117(4):500-44.

26. Choi MS, Meshik X, Mukherjee S, Farid S, Doan S, Covnot L, et al. Electrostatic force analysis, optical measurements, and structural characterization of zinc oxide colloidal quantum dots synthesized by sol-gel method. Journal of Applied Physics. 2015;118(19):194304. 
27. Akito I, Toshihiro A, Shiro U, Yoshimi K. Simulation Analyses of Retinal Cell Responses. Modeling in the Neurosciences: CRC Press; 2005.

28. Tachibana M. Ionic currents of solitary horizontal cells isolated from goldfish retina. J Physiol. 1983;345:329-51.

29. Usui S, Kamiyama Y, Ishii H, Ikeno H. Reconstruction of retinal horizontal cell responses by the ionic current model. Vision Res. 1996;36(12):1711-9.

30. Kurachi Y. Voltage-dependent activation of the inward-rectifier potassium channel in the ventricular cell membrane of guinea-pig heart. J Physiol. 1985;366:365-85.

31. Chen X, Mao SS. Titanium dioxide nanomaterials: synthesis, properties, modifications, and applications. Chem Rev. 2007;107(7):2891-959.

32. Xu K, Purahmad M, Brenneman K, Meshik X, Farid S, Poduri S, et al. Design and Applications of Nanomaterial-Based and Biomolecule-Based Nanodevices and Nanosensors. In: Seminario MJ, editor. Design and Applications of Nanomaterials for Sensors. Dordrecht: Springer Netherlands; 2014. p. 61-97.

33. Tombaugh GC, Somjen GG. pH modulation of voltage-gated ion channels: Wiley-Liss, Inc.; 1998.

34. Iavicoli I, Leso V, Fontana L, Bergamaschi A. Toxicological effects of titanium dioxide nanoparticles: a review of in vitro mammalian studies. Eur Rev Med Pharmacol Sci. 2011;15(5):481-508. 35. Tucci P, Porta G, Agostini M, Dinsdale D, Iavicoli I, Cain K, et al. Metabolic effects of TiO2 nanoparticles, a common component of sunscreens and cosmetics, on human keratinocytes. Cell Death Dis. 2013;4:e549.

36. Lee KP, Trochimowicz HJ, Reinhardt CF. Pulmonary response of rats exposed to titanium dioxide (TiO2) by inhalation for two years. Toxicol Appl Pharmacol. 1985;79(2):179-92.

37. Xu Y, Wei MT, Ou-Yang HD, Walker SG, Wang HZ, Gordon CR, et al. Exposure to TiO2 nanoparticles increases Staphylococcus aureus infection of HeLa cells. J Nanobiotechnology. 2016;14:34.

38. Egerton TA. UV-absorption--the primary process in photocatalysis and some practical consequences. Molecules. 2014;19(11):18192-214. 
39. Imani R, Veranic P, Iglic A, Kreft ME, Pazoki M, Hudoklin S. Combined cytotoxic effect of UVirradiation and $\mathrm{TiO} 2$ microbeads in normal urothelial cells, low-grade and high-grade urothelial cancer cells. Photochem Photobiol Sci. 2015;14(3):583-90.

40. Dalai S, Pakrashi S, Chandrasekaran N, Mukherjee A. Acute toxicity of TiO2 nanoparticles to Ceriodaphnia dubia under visible light and dark conditions in a freshwater system. PLoS One. 2013;8(4):e62970.

41. Nagel G, Ollig D, Fuhrmann M, Kateriya S, Musti AM, Bamberg E, et al. Channelrhodopsin-1: a light-gated proton channel in green algae. Science. 2002;296(5577):2395-8.

42. Wietek J, Wiegert JS, Adeishvili N, Schneider F, Watanabe H, Tsunoda SP, et al. Conversion of channelrhodopsin into a light-gated chloride channel. Science. 2014;344(6182):409-12.

43. Kleinlogel S, Feldbauer K, Dempski RE, Fotis H, Wood PG, Bamann C, et al. Ultra lightsensitive and fast neuronal activation with the $\mathrm{Ca}(2)+-$ permeable channelrhodopsin CatCh. Nat Neurosci. 2011;14(4):513-8.

44. Lin JY, Knutsen PM, Muller A, Kleinfeld D, Tsien RY. ReaChR: a red-shifted variant of channelrhodopsin enables deep transcranial optogenetic excitation. Nat Neurosci. 2013;16(10):1499-508.

45. Berndt A, Yizhar O, Gunaydin LA, Hegemann P, Deisseroth K. Bi-stable neural state switches. Nat Neurosci. 2009;12(2):229-34.

46. Mourot A, Tochitsky I, Kramer RH. Light at the end of the channel: optical manipulation of intrinsic neuronal excitability with chemical photoswitches. Front Mol Neurosci. 2013;6:5.

47. Carvalho-de-Souza JL, Treger JS, Dang B, Kent SB, Pepperberg DR, Bezanilla F. Photosensitivity of neurons enabled by cell-targeted gold nanoparticles. Neuron. 2015;86(1):207-17. 


\begin{tabular}{|c|c|c|c|c|c|c|c|}
\hline & $\alpha_{m}$ & $\beta_{m}$ & $\alpha_{h}$ & $\beta_{h}$ & $g_{\max }[n S]$ & $E_{i}[m V]$ & $I_{\text {ion }}$ \\
\hline $\begin{array}{c}\text { Transient } \\
\text { outward K } \\
\text { current } \\
(27,28)\end{array}$ & $\frac{24}{1+e^{-\frac{V-50}{28}}}$ & $8 e^{-\frac{V}{36}}$ & $0.5 e^{-\frac{V}{60}}$ & $\frac{0.4}{1+e^{-\frac{V+40}{5}}}$ & 3.0 & -80 & $\begin{array}{l}g_{K v} m_{K v}^{3} h_{K v}(V \\
\left.-E_{K v}\right)\end{array}$ \\
\hline $\begin{array}{c}\text { Delayed } \\
\text { rectifying } \\
\mathrm{K}^{+} \text {current } \\
(27-29)\end{array}$ & $\frac{4.0(65-V)}{e^{\frac{65-V}{50}}-1}$ & $48 e^{\frac{45-V}{85}}$ & $\frac{30}{1+e^{\frac{V+92}{7}}}$ & $\frac{16}{1+e^{\frac{V+100}{15}}}$ & 22.0 & -80 & $\begin{array}{l}g_{A} m_{A}^{4} h_{A}(V \\
\left.-E_{A}\right)\end{array}$ \\
\hline $\begin{array}{c}\text { Anomalous } \\
\text { rectifying } \\
\mathrm{K}^{+} \text {current } \\
(27,28)\end{array}$ & & $m_{K a}=-$ & $\frac{1}{+e^{\frac{V+60}{12}}}$ & & 4.5 & -80 & $\begin{array}{l}g_{K a} m_{K a}^{5}(V \\
\left.-E_{K a}\right)\end{array}$ \\
\hline $\begin{array}{l}\mathrm{Ca}^{2+} \\
\text { current } \\
(29)\end{array}$ & $\frac{5(70-V)}{e^{\frac{70-V}{28}}-1}$ & $2 e^{-V / 15}$ & $h_{C a}=\frac{}{[K}$ & $\frac{[K]}{+[C a]_{\text {out }}}$ & 30.0 & $12.9 \log$ & $\begin{array}{l}g_{C a} m_{C a}^{4} h_{C a}(V \\
\left.-E_{C a}\right)\end{array}$ \\
\hline $\begin{array}{c}\mathrm{Na}^{+} \text {current } \\
\text { (27) }\end{array}$ & $\frac{20(38-V)}{e^{\frac{38-V}{25}}-1}$ & $200 e^{-\frac{55+V}{18}}$ & $1.0 e^{-\frac{80+V}{8}}$ & $\frac{0.8}{1+e^{\frac{80-V}{75}}}$ & 5.0 & 55 & $\begin{array}{l}g_{N a} m_{N a}^{3} h_{N a}(V \\
\left.-E_{N a}\right)\end{array}$ \\
\hline $\begin{array}{c}\text { Leakage } \\
\text { current } \\
(25,27)\end{array}$ & & & & & 0.5 & -80 & $g_{l}\left(V-E_{l}\right)$ \\
\hline
\end{tabular}




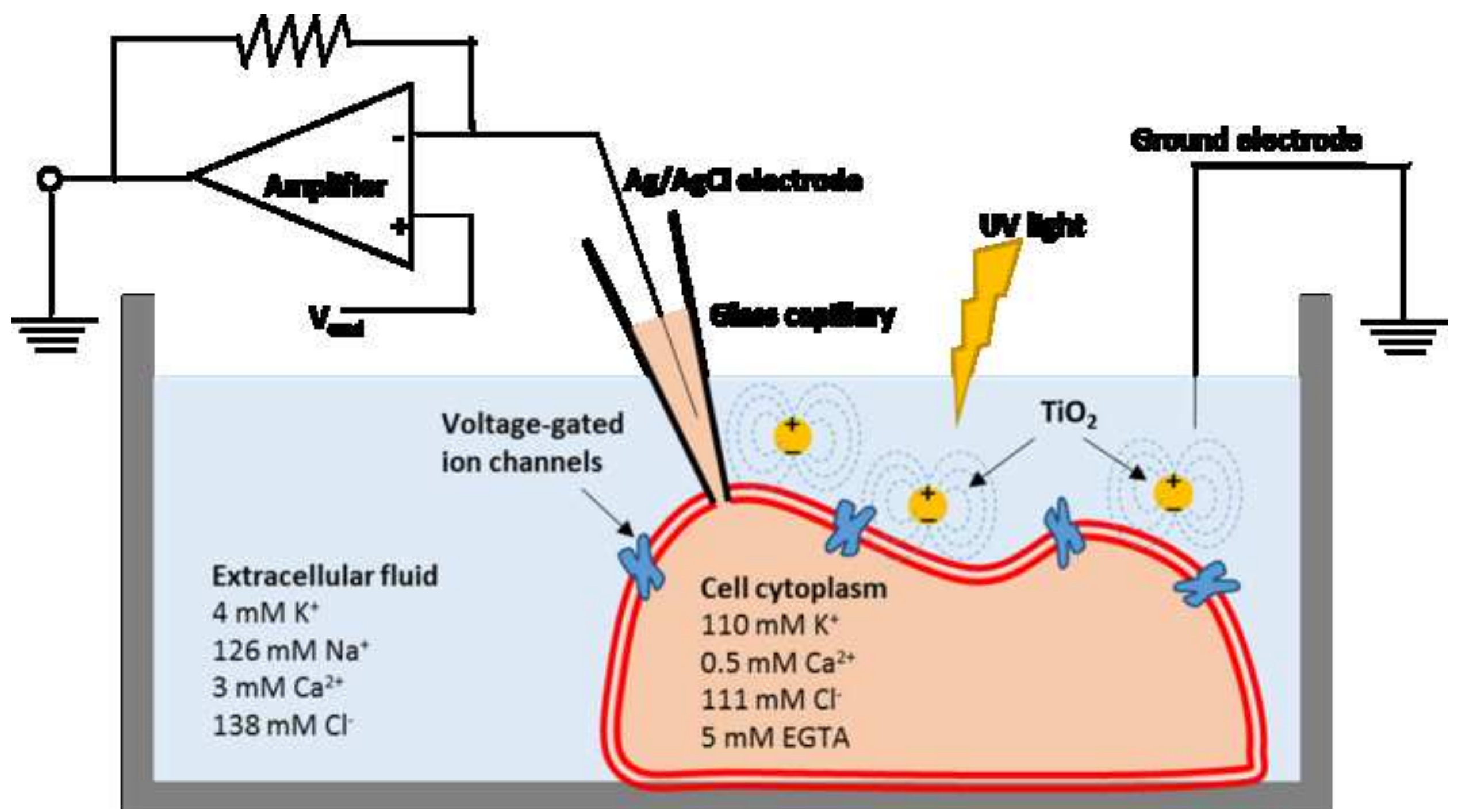



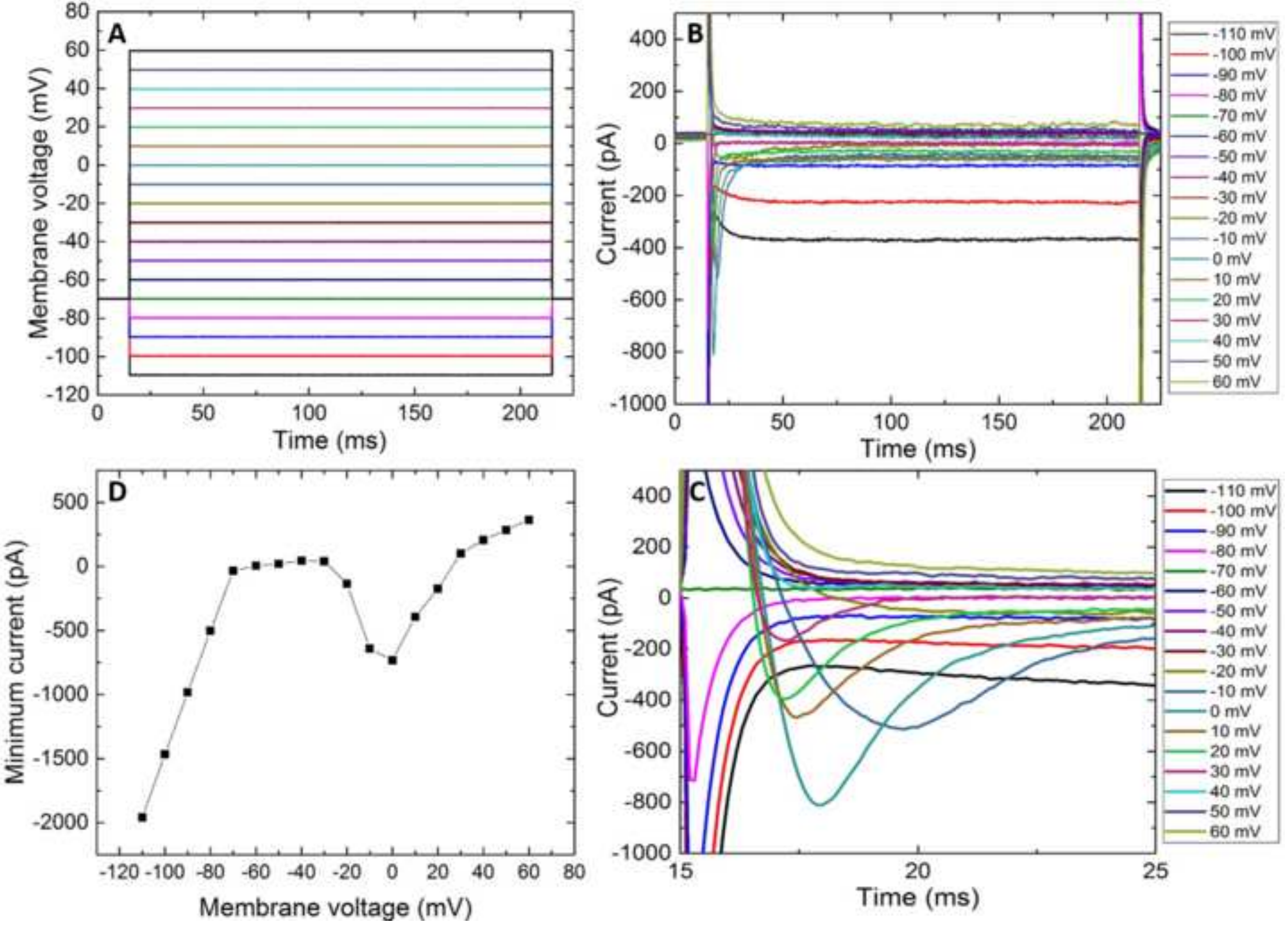

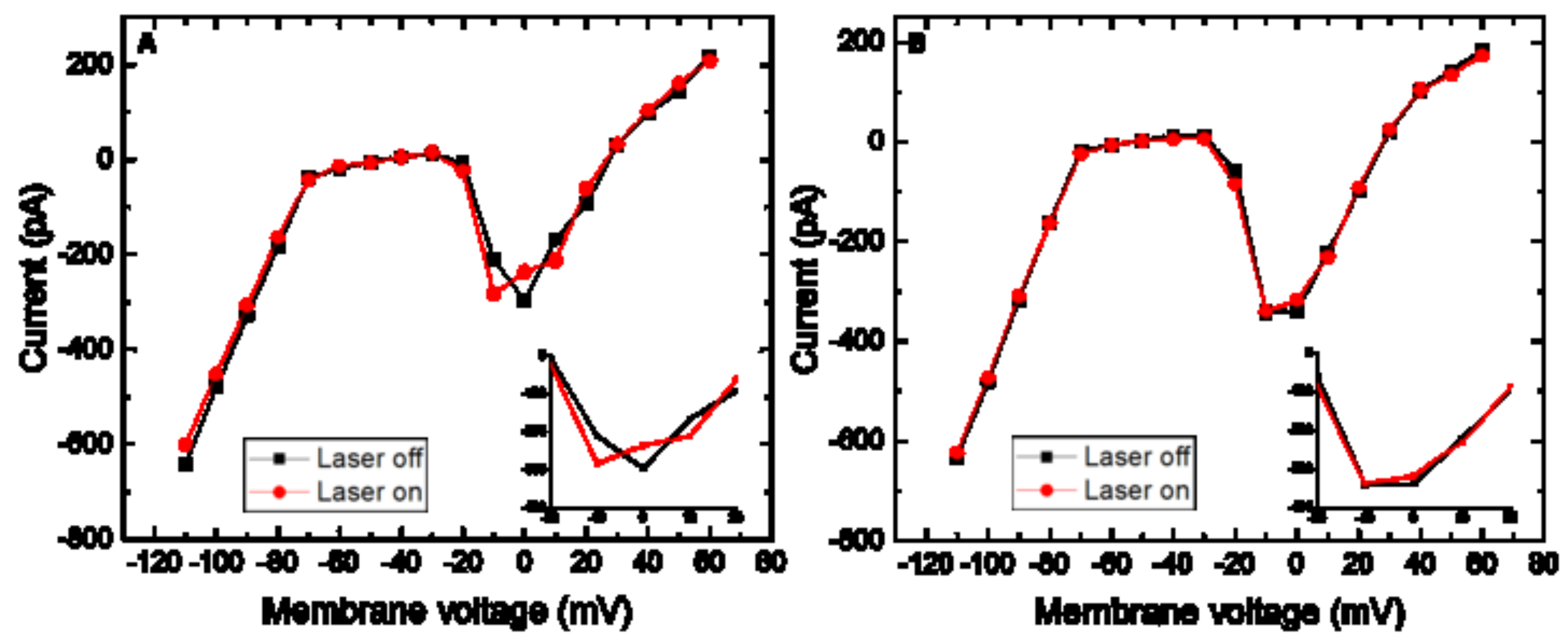


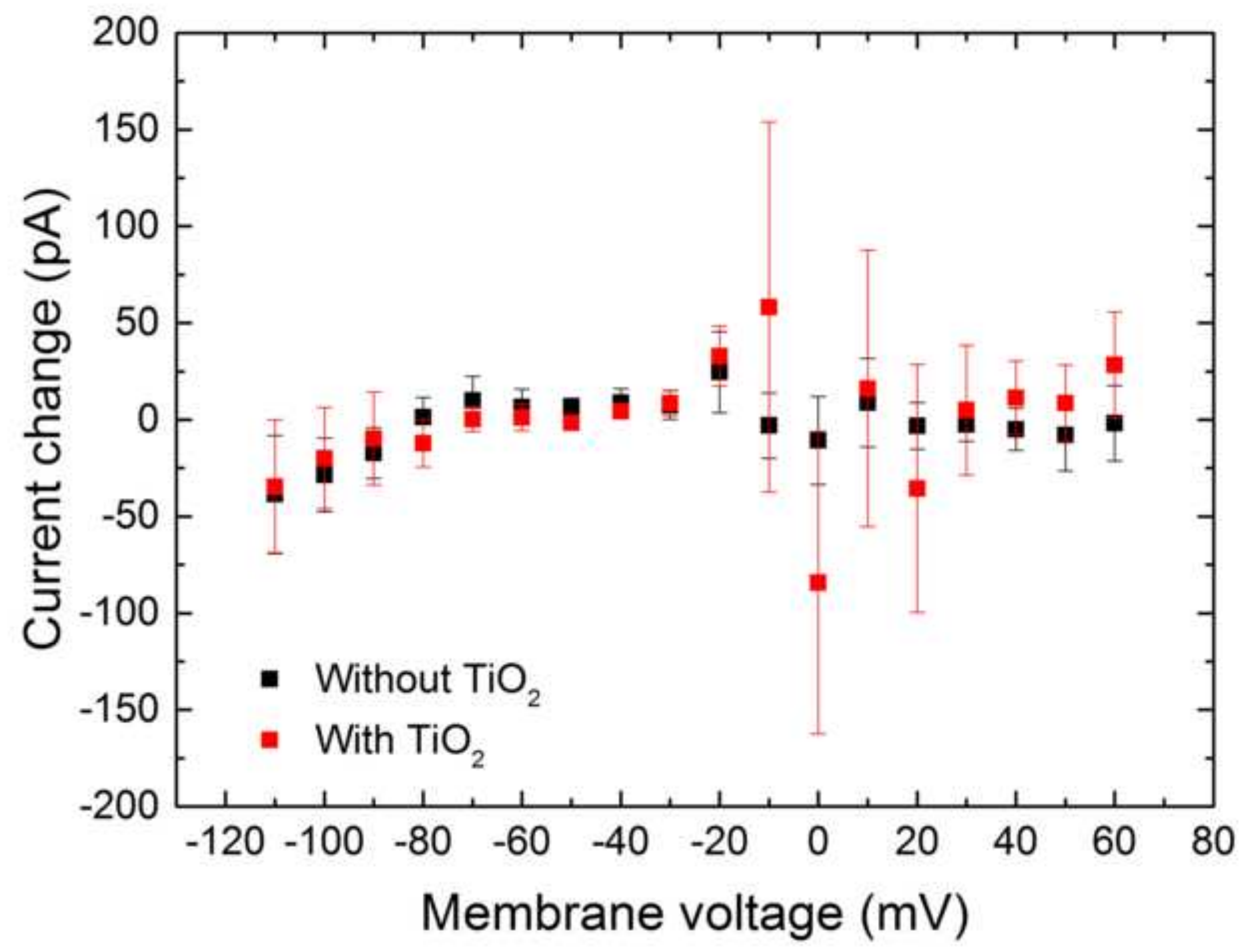




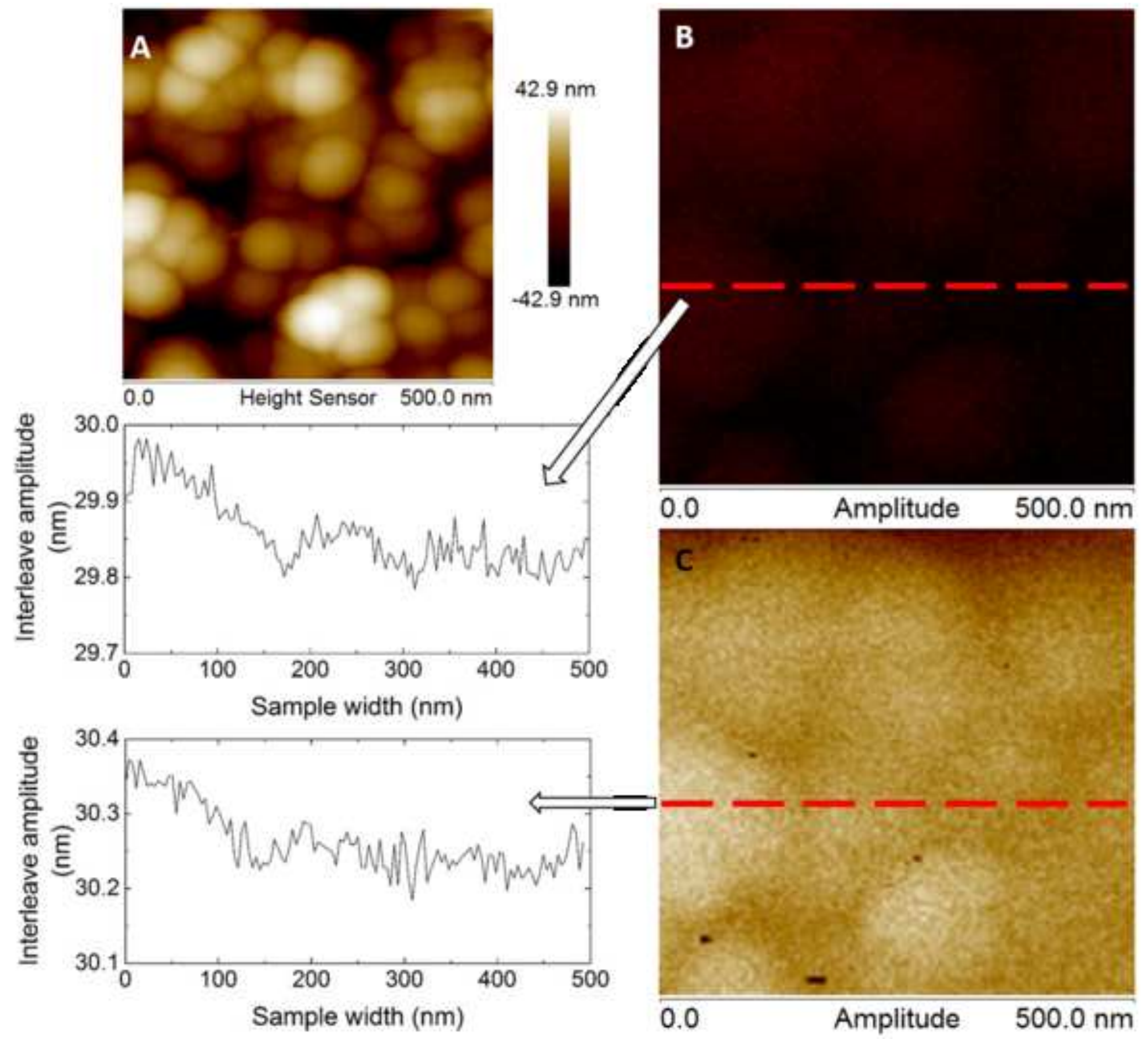

$30.5 \mathrm{~nm}$

$29.7 \mathrm{~nm}$

$30.5 \mathrm{~nm}$

$29.7 \mathrm{~nm}$

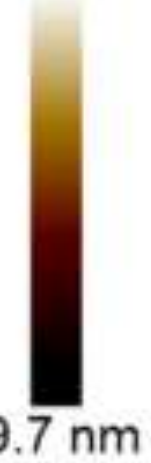



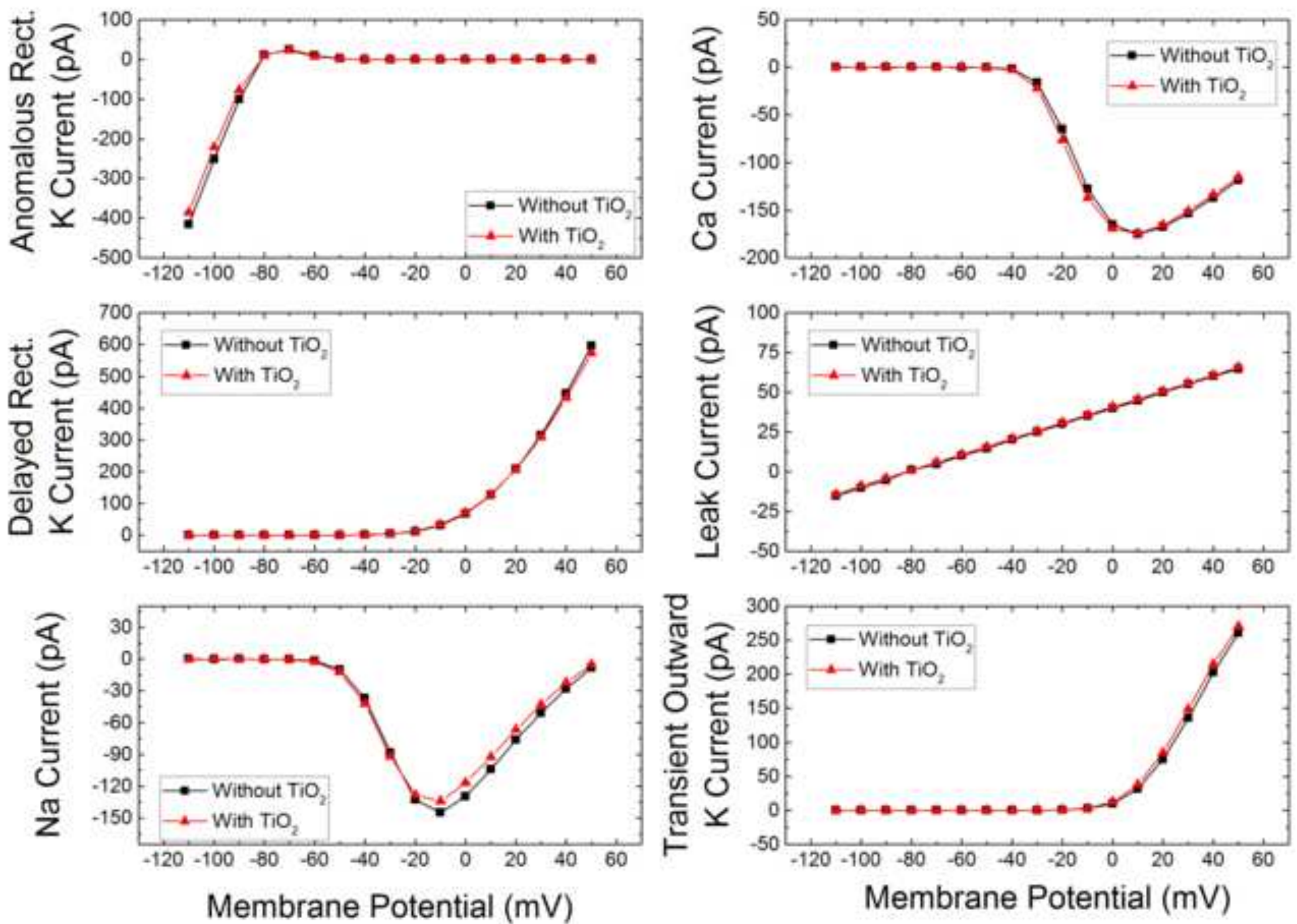

Membrane Potential ( $\mathrm{mV}$ ) 


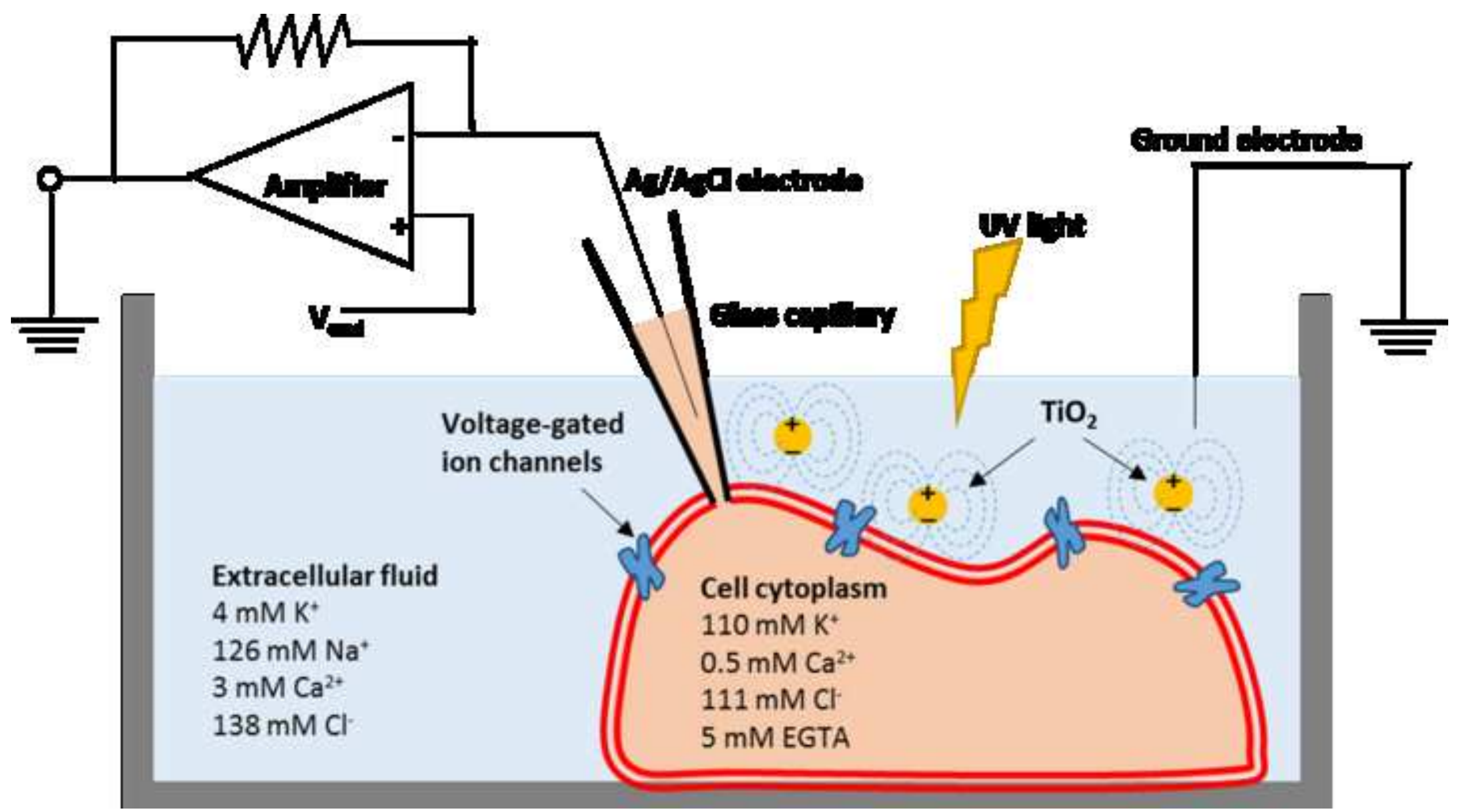

